\title{
Parents perceptions of school nurses roles: The impact of communication on students with autism spectrum disorder
}

\author{
Constance Mclntosh, Jayanthi Kandiah, Lesie J. Remache \\ School of Nursing, College of Health, Ball State University, United States
}

Received: September 15, 2021

Accepted: December 8, 2021

Online Published: January 10, 2022

DOI: $10.5430 /$ jnep.v12n5p55

URL: https://doi.org/10.5430/jnep.v12n5p55

\begin{abstract}
This qualitative study used the nursing grounding theory to describe parents' experiences working with school nurses to elevate their child's healthcare. Seventeen interviews were conducted with parents/primary caregivers (P/PCG) who had children with autism spectrum disorder (ASD; ages six to ten). Through centering parents' voices, the investigators were able to identify gaps in P/CG understanding of their school nurses' roles through thematic analyses. We found that P/CG lacked the understanding of school nurses' roles and how school nurses could aid their child's healthcare. The oversight of school nurses contributed to miscommunication, which constrained the relationship between the parent and the school nurse. These findings provide insight into the importance of enhancing communication between the parents of children with ASD and school nurses and was the catalyst to why this article was written. When healthcare professionals provide clarity and expertise to parents as to their respective roles, incorporate perspective-taking, and tailor their approaches based on their concerns, it may enhance parents' experiences with their school nurses. In addition, school nurses should consider various routes of engaging parents so they have a deeper understanding of their responsibilities in enhancing the healthcare of children with ASD.
\end{abstract}

Key Words: Autism spectrum disorder, Communication, Parents' perceptions, School nurses' roles, School nursing services, Direct care, Nursing interventions

\section{INTRODUCTION}

In the school system, there is an increasing number of students who have chronic diseases. According to the Center for Disease Control and Prevention ${ }^{[1]}$ one in four adolescents has a chronic health condition (e.g., epilepsy, food allergies, obesity). Students with Autism Spectrum Disorder (ASD) may be overlooked despite the growing number of 1 in 54 school-aged children diagnosed with ASD. ${ }^{[1-3]}$ The National Center for Education Statistics ${ }^{[4]}$ report that $11 \%$ of children, under the age of twenty-one, have been diagnosed with ASD.
Inclusively, according to the World Health Organization, ${ }^{[5]}$ 1 in 160 children are diagnosed with ASD. Therefore, ASD may be more common than anticipated in a school-based system. In the present article, the authors aim to fill a gap in a growing field illustrating parents' perceptions of school nurses' roles in providing medical care for their children with ASD. Parents' perceptions are imperative to the utilization of school nurses. In the preceding parts of the article, we will discuss the following topics: (1) the school nurses' roles; (2) ASD symptomatology; (3) parental stress; and (4)

\footnotetext{
*Correspondence: Constance McIntosh; Email: cemcintosh@bsu.edu; Address: School of Nursing, College of Health, Ball State University, Health Professionals Building, Room 490 Muncie, IN 47303, United States.
} 
communication barriers.

\subsection{School nurses roles}

School nurses are imperative healthcare professionals in a school-based system. Students with ASD may experience impairments in their ability to communicate in a schoolbased setting and may display a series of repetitive restrictive behaviors (e.g., hand flapping, stemming). School nurses can address the health concerns of children with ASD to ensure that necessary accommodations are in place to deliver adequate healthcare. ${ }^{[6]}$

The authors exclusively focus on a school-based system because addressing the healthcare needs of students with ASD is imperative for their physical, social, psychological health, and academic success. ${ }^{[7]}$ Students' academic success and their level of engagement in school is associated with meeting the healthcare needs of students with ASD. ${ }^{[8]}$ Also, medically it will be cost effective to parents if they worked closely with school nurses to improve the healthcare needs of their children. ${ }^{[7]}$

School nurses are responsible for helping students with ASD manage their comorbidities, keep track of immunization, health records, administer medication, and provide the necessary accommodations. ${ }^{[9-11]}$ In addition, according to the National Association of School Nurses, ${ }^{[12]}$ school nurses are responsible for providing health screenings, coordinating referrals, and performing case management when collaborating with school staff, family, community leaders, and other healthcare providers. This helps students achieve healthy development and wellbeing in a school-based system. ${ }^{[12,13]}$

\subsection{ASD symptomatology}

Individuals with ASD may have multiple comorbid conditions compared to their typically developing counterparts. ${ }^{\text {[2] }}$ An interprofessional healthcare team can help address the comorbid conditions presented by children with ASD. ${ }^{[2]}$ Unlike their typically developing peers, children with ASD may be at particular risk for being underweight, overweight, or obese due to the impediments of the diagnosis and adverse side effects of medication used to treat comorbidities. ${ }^{[14-17]}$ Students who are overweight are at risk of developing various health disorders such as type 2 diabetes mellitus, cardiovascular disease, hypertension, stroke, gallbladder disease, depression, disordered eating, and lower levels of wellbeing. ${ }^{[2,16,17]}$ Furthermore school nurses can address other cooccurring health care concerns (e.g., gastrointestinal problems, sleep hygiene, epilepsy, and medication compliance) prevalent among ASD children. ${ }^{[2,6]}$ In addition, individuals with ASD are more likely to experience psychiatric disorders than their non-ASD counterparts. ${ }^{[18]}$ Higher levels of psychiatric symptoms may lead to maladaptive behaviors. ${ }^{[2]}$ Presence of mental health problems could also be prevalent, and school nurses can provide early interventions and student referral to mental health professionals. ${ }^{[19]}$ Overall, when school nurses work with students with ASD, they must consider the impact of comorbid conditions on their students' behavior, educational experiences, and wellbeing to help identify treatment options. ${ }^{[2]}$

School nurses can help reduce the potential adverse health conditions from arising (e.g., overweight, underweight, food sensitivity, biological pathways, etc. ${ }^{[2,15,20]}$ by developing sensitive sensory environments and treatment plans. According to NASN, ${ }^{[13]}$ collaboration with community healthcare professionals (e.g., occupational therapists, speech pathologists, school psychologists, social workers, registered and/or licensed dietitian nutritionists) is imperative to fulfill clinical competence guidelines. Although a child's healthcare in a school-based system begins with school nurses and is vital to parents and children, they are part of a broader healthcare team and are not the endpoint of a child's healthcare.

\subsection{Parental stress}

As mentioned, parents of children with ASD work with the complexities of their child's diagnosis. In some cases, children with severe ASD symptomology had higher heart rate variability, which is a physiological symptom of stress. ${ }^{[21]}$ As a result parents of ASD children have levels of stress, aggravation, and depression than parents who have typically developing children. ${ }^{[22-26]}$ Parental stress may heighten (or decrease) based on the severity of the diagnosis, family support, support groups, and community resources. ${ }^{[24,27]} \mathrm{Re}$ search has demonstrated that lower levels of family support were associated with higher levels of parental stress. ${ }^{[28]} \mathrm{A}$ key contributor to parental stress is the severity of the diagnosis, which does not depend on the parents' level of education, employment, ethnicity and is not exclusive to rural areas. ${ }^{[22,24]}$ Family income and levels of parental stress predict the quality of life of a family. ${ }^{[29]}$ Another source of stress is parents' concerns about the healthcare of their children with ASD that remain unaddressed, which will be elaborated in the results section of this paper. Overall, parents experience stress due to the disorder's complexity, which impacts relationships with family, healthcare professionals, and other social networks.

\subsection{Parents perceptions of school nurses}

As discussed earlier, parents may collaborate with their school nurse to ensure their child receives adequate medical attention. Depending on their training and competency, school nurses may have the expertise about ASD, understand 
their child's symptomatology and medication needs. ${ }^{[30]}$ However, a mixed methodological study led by Strunk ${ }^{[30]}$ has shown that school nurses may lack communication skills, safety concerns, and necessary information about potential behavioral therapies. Parents and educators are also unaware of the role that school nurses play in their child's healthcare. ${ }^{[1,30]}$ There is a misperception of school nurses' actual roles in a school-based system. Parents and educators perceive that school nurses are responsible for medication administration and first-aid practices. ${ }^{[11]}$ Parents perceive roles related to emergency events, vision screenings, maintenance of immunizations records, and routine health practices are associated with the school nurse rather than the school staff. The parents involved in their child's school in a volunteering capacity had more accurate perceptions of school nurses' roles. Whereas school staff had more detailed descriptions of their perceptions of school nurses' roles. ${ }^{[1]}$

\subsection{Barriers to communication}

Healthcare professionals are encouraged to engage in effective communication with parents who have children with ASD. Health professionals may enhance levels of communication by enacting active listening, evaluating, carefully explaining treatment options, tailoring their approach based on the parents' values and preferences, and continuing communication with patients through monitoring. ${ }^{[31]}$ A study by Jones and colleagues ${ }^{[32]}$ used communication accommodation theory (CAT) which centers on communication behavior, motivation, and individuals' interpersonal relationships to identify effective and ineffective communication between parents and nurses in neonatal intensive care units (NICU). Researchers reported that effective communication was accommodating, consistent dispersion of information, and encouraged parents to ask questions. ${ }^{[32,33]}$ Ineffective communication between parents and nurses lacked accommodation, and medical information which lacked clarity. ${ }^{[32]}$

An ongoing problem for parents who have children with ASD is the lack of communication with health professionals about their ASD concerns and the decision-making process. A qualitative study by Locke and colleagues ran two-hour focus groups with parents who had a child with ASD below the age of eight, and through thematic analyses, they identified eight recurring themes. ${ }^{[31]}$ First, parents were unfamiliar with the developmental milestones which delayed their child's ASD diagnosis. When parents did identify a disruption to their child's development, their primary care physician (PCP) overlooked concerns until follow-up visits. Second, parents were able to identify concerns once other individuals in their social network of healthcare professionals alluded to the potential for an ASD diagnosis. Third, parents

Published by Sciedu Press reported negative affect and were overwhelmed by the new information on the ASD diagnosis. A critical theme that arose associated to the research was barriers to communication with a PCP. Parents identified delays in the progression of treatment with their PCP. They reported that their healthcare providers were dismissive and not supportive, which led to insufficient communication. Translating the above findings to present research : The communication barriers between parents and school nurses may impair the quality of healthcare that students with ASD may receive.

\subsection{The present study}

Although the expertise of multiple healthcare professionals is encouraged, this study will exclusively focus on parents' perceptions of school nurses to identify ways to enhance levels of communication between school nurses and parents/primary caregivers (P/PCG) of children with ASD. Our present work partially replicated and extended Strunk's findings through thematic analyses, which we will elaborate in the results section. ${ }^{[30]}$ Our rationale for using Strunk's work as a foundation as there is a dearth of information relating to ASD and the extensive role of school nurses in the care of this population. In addition, we aim to demonstrate that parents may misperceive the roles of school nurses. A study by Maughan and Adams has addressed school nurses' interactions with students and parents more generally in a school-based setting, whereas our present work will address the perceived contributions of a school nurse in the healthcare of students with ASD. ${ }^{[10]}$

In this article, we discuss parents/primary caregivers (P/PCG) who have children with ASD and their understanding of the role of school nurses' and identifying barriers in working with school nurses. Because parents lack understanding of school nurses' roles, they may be underutilized, which could detrimentally affect their child's health and experience in a school-based system. In addition, we discuss potential avenues to help improve the relationship between P/CG and nurses in a school-based system to enhance the healthcare of students with ASD. Through the present work, we were able to identify concrete recommendations for school nurses to enhance their relationships with parents and improve the healthcare of students with ASD.

\section{DATA AND METHODS}

\subsection{Participants}

This data was drawn from a total of 17 structured, in-depth interviews ranging from twenty minutes to an hour and a half (Mtime = 26.22). Participants were P/PCG $(\mathrm{N}=17)$ of children diagnosed with ASD between the ages of six to ten. Two participants were excluded as they did not meet the 
inclusion criteria (e.g., caregiver for a child with ASD or did not have a school nurse), thus the final sample was composed of $15 \mathrm{P} / \mathrm{PCG}$.

All participants were 18 years or older, and only one P/PCG from each household participated in the interviews. Of the 15 P/PCG, ( $n=4$ men; 11 women) with a mean of 36.8 years, majority were married $(n=12)$. The others were single ( $n$ $=3$ ) or widowed $(n=2)$. Ethnic distribution included 12 Whites, one Latinx, and two were mixed race. Nine participants reported working full time, with a lesser amount indicating working part-time $(\mathrm{n}=1)$, a student $(\mathrm{n}=1)$, retired $(\mathrm{n}=1)$, had some disability or was unable to work ( $\mathrm{n}$ $=3$ ). Most participants had higher levels of education and income compared to the typical resident in the area where data was collected. This may have occurred because P/PCG were recruited through a college campus as opposed to the community. Educational status of the P/PCG were as follows: high school education $(n=1)$, some college $(n=5)$, bachelor's degree $(n=4)$, master's degree $(n=1)$, and advanced graduate work or $\mathrm{PhD}(\mathrm{n}=4)$. The average salary of the majority $(\mathrm{n}=10)$ of the P/PCG was $\$ 60,000$. One P/PCG indicated their salary as less than $\$ 10,000$ and four $\mathrm{P} / \mathrm{PCG}$ reported their salaries as greater than $\$ 150,000$. All participants were able to read and understand English instructions and read and write at a 6th grade level.

\subsection{Researcher positionality}

This section provides concise descriptions of our identities, as they shape the interpretations and decisions in the current research process. Our positionality informed both the conceptualization of the present work, data collection process, as well as the interpretations of the lived experiences of parents who have children with ASD in a school-based system.

The first author a Registered Nurse (RN) with thirty years of nursing experience including acute care settings (e.g., ER, critical care) collaborated with the second author in conceptualizing the study. The author is an expert in ASD and has conducted research including in an ASD camp setting. This has resulted in multiple articles addressing how school nurses can work with school-aged children diagnosed with ASD.

The second author a Registered Dietitian (RDN) and Licensed Dietitian Nutritionist (LDN) completed her pediatric fellowship at a Children's Hospital in the US. The author partnered with the first author in conceptualizing and designing the research. The author has extensive nutrition research, clinical and community experiences related to preventative health. One of the author's primary areas of expertise and research focus is ASD which is has resulted in the dissemination of refereed publications and presentations. Since schools are challenged with pediatric eating issues the author states it is imperative to have a RDN, a food, nutrition, and diet expert employed in school settings.

The third author has a background in social psychology, focusing on the impact of race, socioeconomic status, and culture on educational attainment and wellbeing. To help counter potential bias in interpreting the parents' lived experiences, the third author transcribed the P/PCG interviews and generated the initial open coding. The first and second authors who hold extensive expertise in nursing, ASD, and nutrition interpreted P/PCG lived experiences to help balance the interpretation process through interrater reliability. Lastly, an external doctoral student and a research mentor with extensive knowledge in qualitative methodologies worked with the third author to ensure consistency in the thematic analysis process.

\subsection{The current study}

Participants were eligible for this study if they had a child (age 6-10) with ASD. Most participants in this study were recruited through snowball sampling from Camp Achieve, which is no cost Autism camp that is part of the University's Center for Autism Spectrum Disorder (CASD).

The data collector was a graduate student in a Clinical Mental Health Counseling program who assisted with the submission of the Institutional Review Board (IRB) documents (e.g., protocol, consent forms, survey questions). There were no biases noted with the data collector regarding children with ASD. The data collector conducted structured interviews composed of eight questions exclusively focused on school nurses. P/PCG were asked about their understanding of the role of their school nurse, three major challenges related to working with their school nurse, previous experience working with the school nurse, their ideal interaction with the school nurse, how the school nurse is related to medication administration, how the school nurse works with sensory sensitivities, involvement in the Individualized Education Program (IEP) or Individualized Health Plan (IHP), and how the school nurse works with their child's behavioral plan.

After participants answered these questions in their structured interviews, the third author transcribed all 15 interviews. After transcribing the interviews, the third author reviewed each transcript to identify themes using a grounded theory approach. Using an iterative constant comparative method, the themes were refined and synthesized across the 15 P/PCG for each of the eight items constructed for the structured interviews (see Appendix A for questions). Once the primary comments from each P/PCG were identified and synthesized with the other respondents, dominant themes 
for each question were explored and verified by the research team. These thematic elements were reviewed finally for overarching conclusions and themes regarding the relationships and functions of school nurses from the perspective of the P/PCG.

\section{Results}

Several themes were identified from the series of 15 interviews. These themes included: (1) limited understanding of school nurses' responsibilities; (2) limited awareness of ASD among school nurses; (3) parental stress; and (4) communication barriers. To provide more context supporting the thematic constructs, we have included quotes to offer a thick and rich description of the caregivers' experience that may inform transferability of experience to similar school contexts.

\subsection{School nurses roles}

We gauged parents' understanding of their school nurse's roles in their child's healthcare by asking P/PCG a series of questions. A sample item was, "What is your understanding of the school nurse's role for your child (children) with ASD?" Many parents reported that they were unaware of their school nurse's role. They reported that if the school nurse was involved in their child's healthcare, it would be limited to dispensing medication, taking care of illness, compliance laws, and vaccination records. Other parents reported not knowing what the school nurse's role was in a school setting.

One participant explained,

"Concerning a nurse at his school, I'm not exactly sure what her specific role is. I know they do have staff there at his school he goes to. But I'm not exactly sure what the daily interaction is between the staff nurse and him."

Another P/PCG reported,

"The school nurse I think is to... make sure they take their meds, and she keeps records on file on who has any kind of disorders or any kind of allergies. She keeps that on track. And then she takes care of any boo-boos that happen on the playground. That's kind of how I see a school nurse."

Whereas other P/PCG reported limited interactions and expectations for their school nurse. A parent reported,

"As little as she can [the school nurse] possibly get away with. She's really not involved."

Overall, after thematic analyses, we have identified that parents were unaware of the role of school nurses in providing treatment for their child with ASD. In some cases, we also identified that parents may not be aware of the school nurse's roles along with setting unrealistic expectations for the school

Published by Sciedu Press nurse which impairs the relationship with the school nurse. For instance, the parents are looking for the nurse to be far more engaged in the daily management of symptoms in the classroom as noted in the quotes in the below section.

\subsection{Awareness of ASD}

Another emergent theme we identified was the perceived lack of awareness of ASD symptomatology of school nurses. P/PCG reported that the school nurse lacks understanding of the complexity of ASD. The culmination of P/PCG lack of awareness of the school nurse's role and the school nurse's lack of awareness concerning ASD tampered with the relationship and has limited contact with the school nurse. P/PCG also believed that school nurses should better understand sensory sensitivity and provide the necessary accommodations for their children with ASD.

A parent reported their school nurse lacked knowledge on the complexities of an ASD diagnosis. However, the nurse sought field experience and resources about ASD, which enhanced their relationship with the parent.

"The first year they had a lack of understanding about the comorbid conditions.... So, she [the nurse] didn't really understand all those things, but she did work to really educate herself. And I mean I think she turned out to be a great partner. Even though we did have some challenges when she didn't quite understand things."

In addition, this parent also reported that the nurse lacked understanding of sensory sensitivity that may accompany an ASD diagnosis. They identified instances in which accommodations were not made (e.g., sensory sensitivity was overlooked).

"There are other things that are going to impact how she's [the child] going to react to the clinic. Or how she's going to react to the nurse. And you know, I'd love to see them understand some of that. In the office that she is in they have these super loud fluorescent lights. They buzz and flickerI mean, kind of like these. I mean, these are awful. I don't know if you've noticed how loud these lights are."

In this case, the parents described how fluorescent lights could be disruptive for students with ASD, and the school nurse who is aware of sensory sensitivity would identify and accommodate the student to avoid overstimulation and distress for the student.

Another P/PCG mentioned the frustrations as a working parent concerning the lack of awareness about ASD.

"My hope would have been that they understand a little more about the diagnosis and are able to work with him... so like when he [the child] has a test, he all of a sudden is used to 
it. . become sick and he [the child] was not really sick but because the nurse doesn't interact with him... the answer was just to call home...So and that's been our experience with six different nurses. So, they're not really [the school nurse] tuned into.

The parent talked about the anxiety their child feels before exams. To cope with their anxiety, they go to the nurse's office. The school nurse cannot identify their child is not sick but is anxious about an exam. In turn, due to the lack of understanding about their child's condition, the school nurse called parents to dismiss their child from school. School nurse with limited expertise in ASD may hinder academic performance, increase, and perpetuate psychological distress, and disrupt the parents work schedule which may tamper with family income.

Parents identified school staff with ASD expertise as playing prominent roles in their child's experience despite not having any medical training. For example, a parent describes,

"He goes [the child] to a special class just to learn how to function with other children's social functioning class. They can't communicate with other kids properly. You know and it just took the patterns, the habits and its everything gotta stay the same... and the nurses just don't play that much of a role in it."

The school nurse does not play a prominent role, but the sensory sensitive environment and staff who lead these classes may play a larger role in their child's experiences in a schoolbased setting.

Overall, ASD education is critical for school nurses, given that 1 in 54 school-aged children are diagnosed with ASD (CDC, 2020). School nurses will encounter students who have ASD and need to be prepared to accommodate, treat, and work with students who have ASD. Nurses who do not have a background in ASD may not be perceptive to the complexities of the diagnoses. This may hinder the healthcare and performance needs of students with ASD in a school. In addition, the lack of accommodations that students with ASD receive further frustrates $\mathrm{P} / \mathrm{PCG}$. Therefore, developing ASD expertise in the nursing curriculum is warranted in the applied setting.

\subsection{Parental/primary caregiver stress}

$\mathrm{P} / \mathrm{PCG}$ of children with ASD reported their unique stressors given the demands of the diagnosis on family life. Finding supportive environments for children with ASD takes time, communication, and a multitude of health professionals who address the comorbidities of the diagnosis. One P/PCG resorted to finding a case manager to help assist their child in a school-based system to aid parental stress. P/PCG who have full-time jobs may find it challenging to balance being a parent/caregiver and ensuring that their child with ASD receives the necessary accommodations in a school-based setting.

The P/PCG reported,

"So, he's [child] hopefully going to be getting a case manager and I would love for the case manager to be able to go and talk to the nurse and make sure that his needs are being met in that area because I think part of the problem is that my husband and I both work full-time. I can't be there all the time. And so, I have to kind of trust that they're doing what they're supposed to be doing and my opportunities for education are either a scheduled meeting or when they call me on the phone. Like I don't really have a lot of other opportunities for that whereas a case manager that's their job and they can go into the school, and they can really be like, okay, here's what you need here."

In addition, social comparison may invoke negative psychological mechanisms that may contribute to parental stress. If P/PCG of children with ASD compare themselves to P/PCG who have typically developing children, it could direct negative emotions.

For example, one P/PCG reported the following, "Yeah, and so I'm I think I'm a cliché because I think that there's a lot of people like me who have a similar issue and they don't I mean then you throw on the top of on top of all of it that my kid has autism hmm, you know, and sometimes it's you know, I see other moms who they're stressed with just the regular mom stuff."

Parental/primary caregiver stress is an important area of consideration because it may impact their wellbeing and communication with healthcare professionals.

\subsection{Barriers to communication-negative communica- tion}

The last theme that came forth through thematic analyses was lack of understanding and communication barriers.

A P/PCG reported the following after being asked about their major challenges related to working with the school nurse.

"A lack of communication and follow-up questions with him definitely and then a lack of understanding about autism and I think from our experience it has definitely been a lack of willingness to understand autism. It's get him in and get them out."

When P/PCG were asked, "How would you like to see the school nurse work with you, your child with ASD or anyone on your child's healthcare team? Please explain."

One $\mathrm{P} / \mathrm{PCG}$ reported, 
"I would just say communication. You know which includes not only face-to-face kind of interactions but email. So, what would be good would be to have a daily or weekly...weekly email to be like "hey here is how [name of child] has been eating...How your child has been eating, here is the environment with which the food was prepared... Blah blah blah." Now I know that they're busy and they don't really have time to do an individually catered email like that each week."

Another P/PCG reported,

"I would like to see the nurses be more educated as to each of their students... and I would really love to see them be a little more proactive about contacting parents and finding out if any of the issues that they need to be aware of like a version of the color red."

The P/PCG identified time constraints but also identified a desire for higher levels of consistent communication with the school nurse. The authors will further explore potential resources that nurses can incorporate in practice to increase levels of communication with P/PCG in the discussion section.

\subsection{Position communication}

On the other hand, P/PCG who had consistent communication levels with their school nurse reported more positive experiences. For example, one P/PCG recalled their challenges working with the school nurse with the following,

"I haven't had any, his [the child] nurse has been amazing in there.... They've been great together. She's [the nurse] always keeping me updated on anything going on whenever he's run out of meds. She's on it."

P/PCG reported better experiences when they have open lines of communication with the school nurse.

"We haven't really had any issues whenever he's low on medicine or having any issues. She's [school nurse] the first to call me and say this and how Noah is feeling today. She's [the school nurse] just been great because she has an open communication with her."

Another P/PCG reported that they could rely on their school nurse to help with accidents.

"I mean he struggles but he's doing a lot better, but he's had a few accidents in school and that somewhere where he's been about to go and let her [the school nurse] know that he's had an accident and it was to come somewhere and somebody and get cleaned up. She's [the school nurse] always snatching clothes out of the lost and found box or something and just giving him, you know, because he doesn't take extra clothes to school anymore."

Overall, a persistent theme throughout the eight interview questions was the lack of communication between nurses

Published by Sciedu Press and parents. The lack of communications P/PCG perceived contributed to their impaired relationship with their school nurse. As reported above, P/PCG who had consistent levels of communication had positive relationships with their school nurses. We can enhance communication barriers to promote positive P/PCG and nurse relationships to address the healthcare needs of students with ASD.

\section{DisCUSSION}

Results of the present research pose that the roles of school nurses are misinterpreted by P/PCG who have children with ASD. We addressed two research inquiries through a series of in-depth interview questions to illustrate the following, (1) parents and/or primary caregivers understanding of the roles of school nurses; (2) the challenges P/PCG experience when working with school nurses to promote positive health of their children. We identified four recurring themes through thematic analyses: The role of school nurses, the lack of nurses' understanding of ASD symptomatology, parental stress due to the complexities of ASD diagnoses, and communication barriers when working with school nurses.

\subsection{Enhancing levels of communication}

We turn special attention to communication barriers to enhance P/PCG experience when working with school nurses. Constrained levels of communication stifled P/PCG professional relationships with school nurses. Given the findings that we have illustrated, the purpose of the present discussion is to identify methods to improve levels of communication between school nurses and parents who have children with ASD. Nurses who adopt effective methods to improve levels of communication may enable parents to utilize them more to enhance the health of their children.

\subsection{The use of telehealth}

Considering the COVID-19 pandemic, the implementation of telehealth tools has increased across different health disciplines. Telehealth can increase the feasibility of healthcare services, especially for caregivers of patients with chronic illnesses. ${ }^{[34]}$ The implementation of telehealth eases the responsibilities of family caregivers by allowing them to connect with health professionals to address the needs of their family members and seek support groups. ${ }^{[34]}$ In addition, telehealth is also accessible to underserved and rural communities, which is imperative to our work because we conducted in-depth interviews with members of a rural community. ${ }^{[35]}$ Telehealth has decreased travel time, enabled customization, increased patient retention, and there was an opportunity for parents and healthcare professionals (etc., occupational therapists) to develop collaborative relationships. ${ }^{[36,37]}$ Although telehealth holds many promising benefits for parents, we 
must consider drawbacks to this approach and identify vulnerable communities. In rural America - such as Montana, Oklahoma, Utah - many families do not have a computer. The primary barriers with telehealth were practitioner training, accessibility to technology, and whether telehealth led to the quality outcomes compared to an in-person approach. ${ }^{[38]}$ There are also concerns about confidentiality and the potential health disparities that may rise from resorting to the delivery of healthcare through telehealth. ${ }^{[39]}$

\subsection{Methods of enhance communication}

As outlined in the results section, many P/PCG reported a lack of understanding of school nurses' roles in treating their children with ASD. Stakeholders also misunderstand the roles of school nurses, resulting in eliminating many schools' nurses' positions. Moss and colleagues have identified the school nurse website as a platform for nurses to convey their roles to the public. ${ }^{[40]}$ Unfortunately, many school nurses do not have an active website to communicate their roles. ${ }^{[40]}$ Informed by previous research, we encourage school nurses to create a personal website to make their roles and contact information accessible to parents. In turn, parents will utilize school nurses because they understand the bounds of school nurse's professional expertise (e.g., inviting nurses to be involved in individualized education program).

Nurses are also encouraged to collaborate with school staff to establish interprofessional relationships. ${ }^{[41]}$ By becoming part of a collaborative process, they can also address P/PCG concerns with a broader perspective of their child's experience in a school setting. Nurses can collaborate by setting regular meetings and following up about any potential concerns. ${ }^{[41]}$

In addition, as stated in the results section, P/PCG who had positive relationships with their school nurse had consistent levels of communication. School nurses provided updates of their ASD child to P/PCG, thus creating open lines of communication. The open lines of communication led parents to believe that the school nurses were reliable members of their healthcare team. We encourage school nurses to engage in dialogue with parents through email, joining the IEP plan, and tailoring their approach based on parents' concerns.

\subsection{Limitations}

Several limitations existed in the present work. We oversampled parents who had higher levels of education, therefore, leading to external validity concerns. Future research can recruit a representative sample across all socio-economic status to address P/PCG perceptions of their school nurses in treating children with ASD. Despite this limitation, the strengths outweighed in that we utilized rigorous methodology to strengthen our interval validity, such as implementing eight interview questions to identify P/PCG comprehensive experiences with school nurses. We also had two professionals with expertise in ASD and a total of six professionals with diverse lived experiences engage in open coding to ensure interrater reliability.

\subsection{Concluding remarks}

In summary, there is a lack of understanding of school nurses' explicit roles in a school setting. Impaired levels of communication undermine the working relationship between parents/primary caregivers and school nurses, therefore leading to the underutilization of school nurses in treating children with ASD. Despite the work conducted by Maughan and Adams, ${ }^{[10]}$ we are still seeing similar emerging themes, such as P/PCG lack of awareness of school nurses' roles. We also establish constrained communication systems. The present article aims to illustrate these problems to pave potential avenues of empirically tested methods to enhance communication between parents/primary caregivers and school nurses in improving the health care needs of children with ASD.

\section{ACKNOWLEDGEMENTS}

The authors want to acknowledge the support of the Research Design Studio at Ball State University for their contributions during the qualitative data analysis process and for helping revise the paper. We would also like to thank Naomi Boucher for conducting all structured interviews.

\section{CONFLICTS OF INTEREST DisClOSURE}

The authors declare that there is no conflict of interest.

\section{REFERENCES}

[1] CDC. (2020, September 25). Data and statistics on Autism Spectrum Disorder. Available from: https://www.cdc.gov/ncbddd/aut ism/data.html

[2] Casanova MF, Frye RE, Gillberg C, et al. Editorial: Comorbidity and Autism Spectrum Disorder [Editorial]. Frontiers in Psychiatry. 2020 PMid:33329163 Available from: https://doi.org/10.3389/fp syt. 2020.617395

[3] Minchella L, Preti L. Autism spectrum disorder: Clinical considerations for the school nurse. NASN School Nurse. 2011; 26(3): 143145. PMid:21675293 https://doi.org/10.1177/1942602X11 402834

[4] National Center for Education Statistics. Students with Disabilities: Preprimary, Elementary, and Secondary Education. 2021. Available 
from: https://nces.ed.gov/programs/coe/indicator/cgg

[5] WHO. Autism spectrum disorders. 2021. Available from: https://www . who.int/news-room/fact-sheets/detail/a utism-spectrum-disorders

[6] McIntosh CE, Thomas CM, Brattain CK. Nurses identify education and communication among professionals as essential in serving ASD children. NASN School Nurse. 2016; 31(3): 164-169. PMid:25869846 https://doi.org/10.1177/1942602X155807 98

[7] CDC. Healthy schools how CDC helps students get a healthy start. Centers for Disease Control and Prevention. 2019. Available from: https://www.cdc.gov/chronicdisease/resources/p ublications/factsheets/healthy-schools.htm

[8] Berglund Melendez A, Malmsten M, Einberg EL, et al. Supporting students with neurodevelopment disorders in school health care-school nurses' experiences. International Journal of Environmental Research and Public Health. 2020; 17(16): 5752. PMid:32784860 https://doi.org/10.3390/ijerph17165752

[9] Baisch MJ, Lundeen SP, Murphy MK. Evidence-based research on the value of school nurses in an urban school system. Journal of School Health. 2011; 81(2): 74-80. PMid:21223274 https: //doi.org/10.1111/j.1746-1561.2010.00563.x

[10] Maughan ED, Adams R. Educators' and parents' perception of what school nurses do: The influence of school nurse/student ratios. The Journal of School Nursing. 2011; 27(5): 355-363. PMid:21788399 https://doi.org/10.1177/1059840511416368

[11] Maughan ED, McCarthy AM, Hein M, et al. Medication management in schools: 2015 survey results. The Journal of School Nursing. 2018; 34(6): 468-479. PMid:28891368 https ://doi .org/10.1177/10 59840517729739

[12] NASN. NASN position statement: Role of the school nurse. NASN School Nurse. 2012; 27(2): 103-104. PMid:22567786 https : //do i.org/10.1177/1942602X11412524

[13] NASN. Framework for 21st century school nursing practice: National Association of School Nurses. NASN School Nurse. 2016; 31(1): 45-53. PMid:26739934 https ://doi .org/10.1177/1942 $602 \times 15618644$

[14] Hill AP, Zuckerman KE, Fombonne E. Obesity and autism. Pediatrics. 2015; 136(6): 1051-1061. PMid:26527551 https://doi .org/10 $.1542 /$ peds . 2015-1437

[15] Grondhuis SN, Aman MG. Risk factors for overweight in children with Autism Spectrum Disorder. Journal of Developmental and Physical Disabilities. 2017; 29(2): 241-263. https://doi.org/10.1 007/s10882-016-9522-0

[16] Matheson BE, Douglas JM. Overweight and obesity in children with autism spectrum disorder (ASD): A critical review investigating the etiology, development, and maintenance of this relationship. Review Journal of Autism and Developmental Disorders. 2017; 4(2): 142156. https://doi.org/10.1007/s40489-017-0103-7

[17] Zickgraf HF, Richard E, Zucker NL, et al. Rigidity and sensory sensitivity: Independent contributions to selective eating in children, adolescents, and young adults. Journal of Clinical Child and Adolescent Psychology. 2020; 1-13. PMid:32189525 https: //doi.org/10.1080/15374416.2020.1738236

[18] Leyfer OT, Folstein SE, Bacalman S, et al. Comorbid psychiatric disorders in children with autism: Interview development and rates of disorders. Journal of Autism and Developmental Disorders. 2006; 36(7): 849-861. PMid:16845581 https://doi.org/10.1007/s1 0803-006-0123-0

[19] Puskar KR, Marie Bernardo L. Mental health and academic achievement: Role of school nurses. Journal for Specialists in Pediatric
Nursing. 2007; 12(4): 215-223. PMid:17956370 https ://doi .or $\mathrm{g} / 10.1111 / \mathrm{j} .1744-6155.2007 .00117 . \mathrm{x}$

[20] Anderson D. Keeping the child with autism spectrum disorder safe. AAACN Viewpoint. 2015; 37(1): 11-13. Available from: https://www.proquest.com/scholarly-journals/keepin g-child-with-autism-spectrum-disorder-safe/docvie w/1691422197/se-2?accountid=8483

[21] Factor RS, Swain DM, Scarpa A. Child autism spectrum disorder traits and parenting stress: The utility of using a physiological measure of parental stress. Journal of Autism and Developmental Disorders. 2018; 48(4): 1081-1091. PMid:29164443 https: //doi.org/10.1007/s10803-017-3397-5

[22] Ault S, Breitenstein S, Tucker S, et al. Caregivers of children with autism spectrum disorder in rural areas: A literature review of mental health and social support. Journal of Pediatric Nursing,. 2021; 61: 229-239. PMid:34153794 https://doi.org/10.1016/j.pe dn.2021.06.009

[23] Giovagnoli G, Postorino V, Fatta LM, et al. Behavioral and emotional profile and parental stress in preschool children with autism spectrum disorder. Research in Developmental Disabilities. 2015; 45: 411-421. PMid:26318505 https://doi.org/10.1016/j.ridd.2015.08 .006

[24] Saccà A, Cavallini F, Cavallini MC. Parents of children with autism spectrum disorder: A systematic review. Journal of Clinical \& Developmental Psychology. 2019; 1(3): 30-44. https ://doi .org/10.6 092/2612-4033/0110-2174

[25] Schieve LA, Blumberg SJ, Rice C, et al. The relationship between autism and parenting stress. Pediatrics. 2007; 119(Supplement 1): S114-S121. PMid:17272578 https://doi.org/10.1542/peds .2006-2089Q

[26] Serrata CA. Psychosocial aspects of parenting a child with autism. Journal of Applied Rehabilitation Counseling. 2012; 43(4): 29-35. https://doi.org/10.1891/0047-2220.43.4.29

[27] Derguy C, M'bailara K, Michel G, et al. The need for an ecological approach to parental stress in autism spectrum disorders: the combined role of individual and environmental factors. Journal of Autism and Developmental Disorders. 2016; 46(6): 1895-1905. PMid:26858031 https://doi.org/10.1007/s10803-016-2719-3

[28] Zeng S, Hu X, Zhao H, et al. Examining the relationships of parental stress, family support and family quality of life: A structural equation modeling approach. Research in Developmental Disabilities. 2020 PMid:31785472 https://doi.org/10.1016/j.ridd.2019.10 3523

[29] Hsiao YJ. Autism spectrum disorders: Family demographics, parental stress, and family quality of life. Journal of Policy and Practice in Intellectual Disabilities. 2018; 15(1): 70-79. https://doi . org/10 $.1111 /$ jppi. 12232

[30] Strunk JA. School nurses' knowledge of autism spectrum disorders. The Journal of School Nursing. 2009; 25(6): 445-452. PMid:19776227 https://doi.org/10.1177/10598405093482 21

[31] Locke J, Ibanez LV, Posner E, et al. Parent perceptions about communicating with providers regarding early autism concerns. Pediatrics. 2020; 145(Supplement 1): S72-S80. PMid:32238533 https://doi.org/10.1542/peds.2019-1895J

[32] Jones L, Woodhouse D, Rowe J. Effective nurse parent communication: A study of parents' perceptions in the NICU environment. Patient Education and Counseling. 2007; 69(1-3): 206212. PMid:17936549 https://doi.org/10.1016/j.pec. 2007 .08 .014

[33] Jones L, Taylor T, Watson B, et al. Negotiating care in the special care nursery: Parents' and nurses' perceptions of nurse-parent 
communication. Journal of Pediatric Nursing. 2015; 30(6): e71-e80.

PMid:25934580 https://doi.org/10.1016/j.pedn.2015.03 .006

[34] Chi NC, Demiris G. A systematic review of telehealth tools and interventions to support family caregivers. Journal of Telemedicine and Telecare. 2015; 21(1): 37-44. PMid:25475220 https ://doi .org/ $10.1177 / 1357633 \times 14562734$

[35] Little LM, Wallisch A, Pope E, et al. Acceptability and cost comparison of a telehealth intervention for families of children with autism. Infants \& Young Children. 2018; 31(4): 275-286. https : //doi.org/10.1097/IYC.0000000000000126

[36] Brunton C, Arensberg MB, Drawert S, et al. Perspectives of registered dietitian nutritionists on adoption of telehealth for nutrition care during the COVID-19 pandemic. Healthcare. 2021; 9(2): 235. PMid:33672179 https://doi .org/10.3390/healthcare9020 235

[37] Wallisch A, Little L, Pope E, et al. Parent perspectives of an occupational therapy telehealth intervention. International Journal of
Telerehabilitation. 2019; 11(1): 15. PMid:31341543 https ://doi. org/10.5195/ijt.2019.6274

[38] Hermes SS, Rauen J, O'Brien S. Perceptions of school-based telehealth in a rural state: Moving forward after COVID-19. International Journal of Telerehabilitation. 2021; 13(1). PMid:34345344 https://doi.org/10.5195/ijt.2021.6370

[39] Barney A, Buckelew S, Mesheriakova V, et al. The COVID-19 pandemic and rapid implementation of adolescent and young adult telemedicine: Challenges and opportunities for innovation. Journal of Adolescent Health. 2020; 67(2): 164-171. PMid:32410810 https://doi.org/10.1016/j.jadohealth.2020.05.006

[40] Moss E, Bergren MD, Maughan ED. School nurse websites: What do they tell us about school nurses? The Journal of School Nursing. 2019; 35(6): 395-400. PMid:30983512 https://doi.org/10.1 $177 / 1059840519843315$

[41] Helleve A, Midthassel UV, Federici RA. Finding the balance between collaboration and autonomy among school nurses in interactions with schools. The Journal of School Nursing. 2020; 1-10. PMid:32308104 https://doi.org/10.1177/1059840520918924 